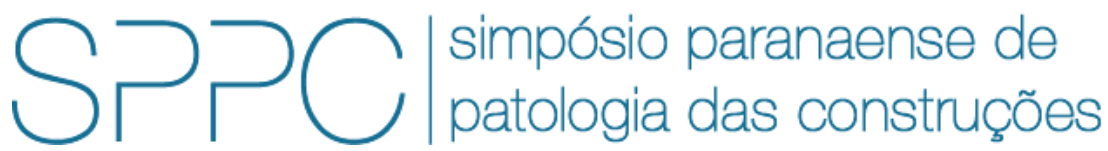

ISSN 2526-7248 artigo 2SPPC1014, pp. 159-170, 2017

\title{
Análise de manifestações patológicas em Obras de Arte Especiais - Estudo de caso e propostas de recuperação
}

\author{
Amanda Christine Gallucci Silva ${ }^{1}$, Giovana Rafaela Campos ${ }^{2}$ e Mauro Lacerda Santos Filho ${ }^{3}$ \\ ${ }^{1}$ Graduanda em Engenharia Civil, Universidade Federal do Paraná, amandagallucci@gmail.com \\ 2 Graduanda em Engenharia Civil, Universidade Federal do Paraná, \\ giovanacampos@alunos.utfpr.edu.br \\ ${ }^{3}$ Prof. Dr. Ph.D, Universidade Federal do Paraná, maurolacerda1982@gmail.com
}

Resumo: Assim como as demais estruturas da construção civil, as pontes e os viadutos são projetadas para suas respectivas vidas úteis. Porém, há vários fatores responsáveis por prolongá-la ou reduzi-la. A má execução da estrutura e falta de manutenção são fatores que podem acarretar na diminuição da vida de uma Obra de Arte Especial (OAE). Entretanto, é possível minimizar tais problemas através de técnicas de reparo. Visando otimizar a infraestrutura de transportes brasileira, o seguinte trabalho realiza a análise de uma OAE localizada no estado de Santa Catarina e propõe possíveis técnicas de reparo para a estrutura deteriorada. A estrutura foi projetada para a Classe 24, na qual os esforços sob o tabuleiro foram calculados às cargas móveis de um compressor de 24 tf, sendo que, o relatório de manifestações patológicas foi executado pelo Escritório Modelo de Engenharia Civil (EMEA) em parceria entre o Escritório, a Universidade Federal do Paraná (UFPR) e o Departamento Nacional de Infraestrutura de Transportes (DNIT). Portanto, o seguinte trabalho visa relatar as manifestações patológicas encontradas em inspeção e propor possíveis métodos de reparo.

Palavras-chave: Manifestações patológicas, Obras de Artes Especiais, recuperação estrutural, técnicas de reparo, estudo de caso.

Abstract: As well as other structures, bridges and viaducts are designed to have a certain useful life. Nevertheless, there are several factors responsible for prolonging or reducing it. The poor execution of the structure and the lack of maintenance are factors that can lead to a decrease in the useful life of these structures. However, it's possible to minimize those problems through repair techniques. In order to optimize the Brazilian transport infrastructure the following study performs an analysis of a bridge located in the state of Santa Catarina and proposes possible repair techniques for the deteriorated structure. The bridge was designed for class 24 , on which the stresses under the tray were calculated using mobile loads of a 24 tons press force compressor. The report of pathological manifestations was executed by Escritório Modelo de Engenharia Civil (EMEA) in partnership among EMEA, the Federal University of Paraná (UFPR) and the National Department of Transport Infrastructure (DNIT). So that, this paper aims to describe pathological manifestations found by inspection and propose recovery methods.

Keywords: pathological manifestations, bridges, repair techniques, structural recovery. 
SILVA, A. C. G.; CAMPOS, G. R.; SANTOS FILHO, M. L., ANÁLISE DE MANIFESTAÇÕES PATOLÓGICAS EM OBRAS DE ARTE ESPECIAIS - ESTUDO DE CASO E PROPOSTAS DE RECUPERAÇÃO. $2^{\circ}$ Simpósio Paranaense de Patologia das Construções (2 ${ }^{\circ}$ SPPC), artigo 2SPPC1014, pp. 159-170, 2017. DOI: 10.4322/2SPPC.2017.014

\section{Introdução}

A necessidade de cuidar das Obras de Artes Especiais já construídas é dada em âmbito nacional. Pois, de acordo com Fonte [1], a eficiência da malha rodoviária é fundamental em um país que utiliza o sistema rodoviário como seu sistema principal de transporte. A fim de se ter um controle sobre a situação das OAEs já construídas, faz-se necessário acompanhá-las por meio de inspeções.

A primeira inspeção que deve ser realizada numa ponte ou viaduto é a Inspeção Cadastral. Essa primeira inspeção possui o objetivo de documentar os informes construtivos e deve ser executada logo após a construção da estrutura ou quando constatada a necessidade de alargamento e reforços. DNIT [2].

A próxima inspeção que deve ser realizada. De acordo com o DNIT [2], a Inspeção Rotineira é programada, geralmente a cada dois anos, a fim de constatar anomalias e alterações em relação à inspeção anterior. São visuais e, em alguns casos, podem exigir equipamentos especiais, como por exemplo, barco e binóculo. A inspeção deve ficar registrada através de um Relatório Fotográfico e de Uma Ficha de Inspeção Rotineira.

Em caso que a OAE apresente sinais de esforços imprevistos, comportamento problemático ou uma estrutura com grande porte ou sistema estrutural excepcional, deve-se realizar uma Inspeção Especializada, de acordo com o DNIT [2]. A inspeção deve ocorrer sob acompanhamento de engenheiro especializado em estruturas.

A partir dos dados obtidos em inspeção, é possível conhecer possíveis desconformidades da estrutura para assim intervir por meio de reparo ou reforço. No estudo a seguir, será analisado dados obtidos por uma Inspeção Rotineira, sendo que, após executado os reparos das manifestações diagnosticadas, é necessário atentar-se nas próximas inspeções se elas não voltem a ocorrer. Caso seja observada a recorrência, deve-se estudar e erradicar as causas das manifestações.

\section{Características da estrutura}

A obra de arte estudada transpõe o rio Itajaí Açu II e possuí o sistema construtivo em concreto armado, assim como pode ser evidenciado na Fig. 1. A estrutura é composta por tabuleiro, duas vigas longitudinais em formato "T", trinta e sete transversinas portantes, quatorze pilares com seção circular, quatorze aparelhos de apoios de Neoprene Fretado, juntas de dilatação elastoméricas, dois encontros em cortina, dois aterros de acesso, sete vigas de contraventamentos unindo cada dois pilares, sete blocos de fundação ligando estacas aos pilares, pavimento asfáltico, além de sistema de sinalização, operação e drenagem. A estrutura tem 200 metros de extensão e 9,40 metros de largura e tem traçado curvo, e, levando em consideração suas medidas e a barreira de apoio não padronizada com o sistema do DNIT [2], pode-se estimar que a ponte fora construída para Classe 24 (compressor de 24 tf), sendo que, no Brasil, o atual compressor pesa 45 tf. 
SILVA, A. C. G.; CAMPOS, G. R.; SANTOS FILHO, M. L., ANÁLISE DE MANIFESTAÇÕES PATOLÓGICAS EM OBRAS DE ARTE ESPECIAIS - ESTUDO DE CASO E PROPOSTAS DE RECUPERAÇÃO. $2^{\circ}$ Simpósio Paranaense de Patologia das Construções (2 ${ }^{\circ}$ SPPC), artigo 2SPPC1014, pp. 159-170, 2017. DOI: 10.4322/2SPPC.2017.014

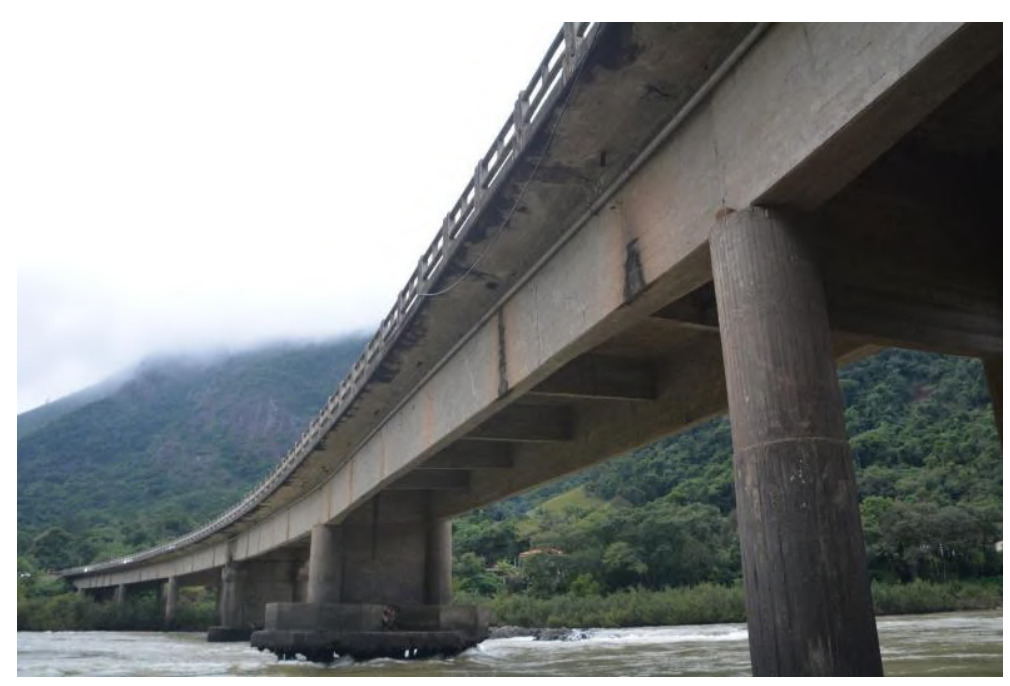

Figura 1: Vista da cabeceira da ponte

\section{Relatório de Manifestações Patológicas}

O relatório das manifestações patológicas foi realizado a partir da inspeção da OAE. A metodologia utilizada para inspeção da estrutura é baseada na desenvolvida pelo Escritório Modelo de Engenharia Civil da Universidade Federal do Paraná, e consiste em 3 etapas: pré-inspeção, inspeção e pós-inspeção. Para o estudo de caso em questão, se faz necessário seguir as etapas de pré-inspeção, inspeção e parcialmente a etapa de pós-inspeção. Na primeira etapa foram levantados documentos iniciais, como por exemplo inspeções anteriores, projeto e memorial de cálculo, ocorreu também a definição das atribuições internas da equipe e preparação dos equipamentos e fichas cadastrais. Durante a inspeção foram preenchidos os seguintes documentos:

- Ficha de cadastro baseada na norma DNIT 010/2004 - PRO (Fig. 2);

- Pranchas de croqui;

- Planilha de registro fotográfico;

- Planilha de cadastro de manifestações patológicas.

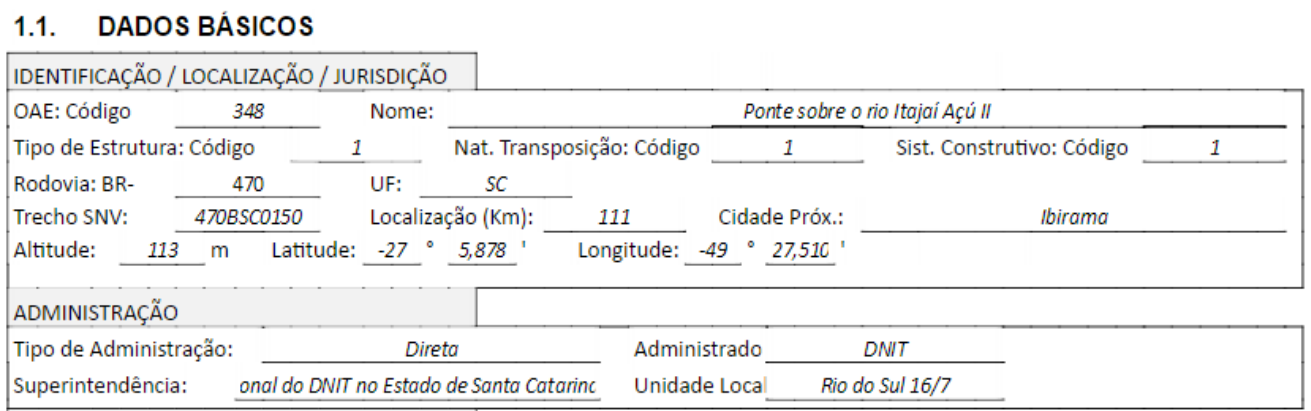

Figura 2: Segmento da ficha cadastral baseada no DNIT 010/2004-PRO

A seguir serão apresentadas brevemente as manifestações patológicas encontradas na ponte estudada e respectivos métodos de reparo. 


\subsection{Corrosão de armaduras}

Segundo Helene [3], a corrosão é uma interação destrutiva entre um material e o ambiente que está inserido por meio de reação química ou eletroquímica. Segundo Santos [4], a proteção da armadura contra a corrosão eletroquímica é garantida pela camada física de concreto (cobrimento) que impede o contato direto com o ambiente e pela barreira química que consiste na alcalinidade do concreto devido à presença de hidróxido de cálcio $\left(\mathrm{Ca}(\mathrm{OH})_{2}\right)$ resultante das reações de hidratação do cimento. Essas barreiras levam à formação de uma película passivadora que envolve a armadura. A corrosão eletroquímica só ocorre se houver despassivação da armadura.

O desplacamento do concreto, neste caso, ocorre devido às tensões internas ao concreto exercidas pelos produtos expansivos da corrosão. Quando a tensão limite de tração do concreto é superada pelas tensões geradas pelos produtos expansivos, ocorre, segundo Polito [5] a fissuração do concreto em direções paralelas à armadura corroída. A evolução dessas fissuras acarreta no desplacamento do concreto de cobrimento.

$\mathrm{Na}$ inspeção realizada foram encontradas grandes áreas de exposição de armadura devido ao desplacamento do concreto. Os principais elementos afetados são as lajes e as longarinas. Segundo Helene [3] locais que sofrem esforços de tração são mais sujeitos a corrosão do que partes comprimidas, sendo assim vigas e lajes têm mais risco de corrosão que outros elementos. A Fig. 3 mostram a laje a obra de arte que sofreu corrosão com desplacamento em quase metade da sua extensão. Já na Fig. 4, pode ser observada a manifestação na longarina.

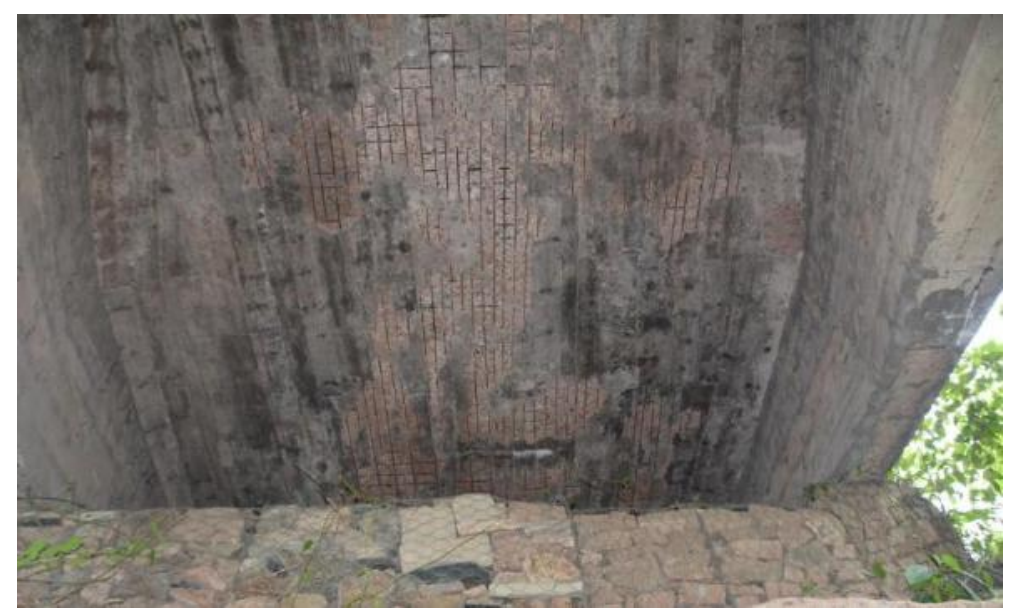

Figura 3: Laje afetada por corrosão com desplacamento. 


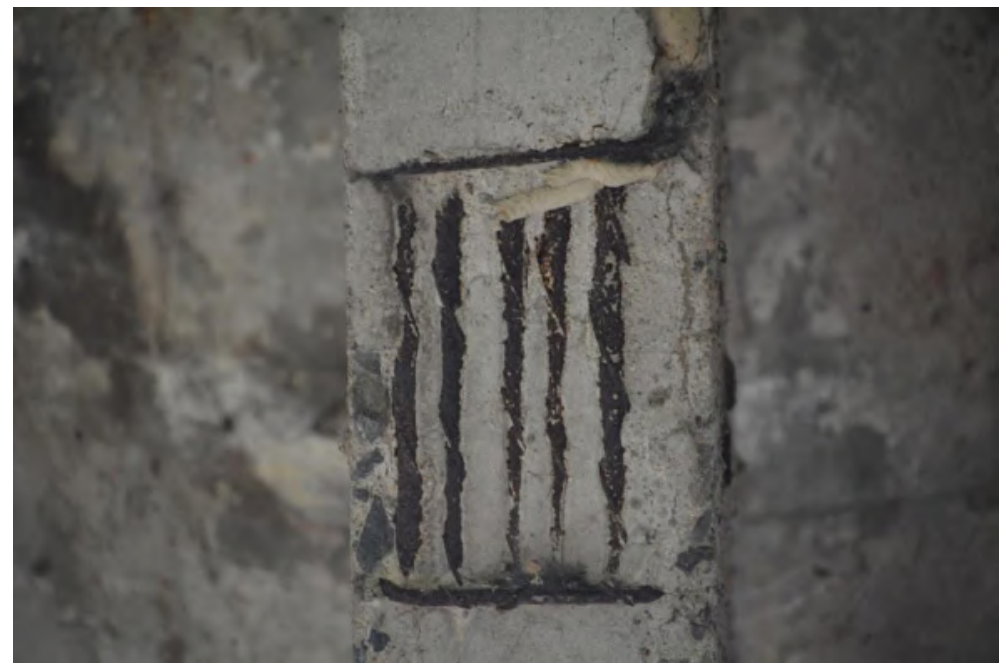

Figura 4: Viga afetada por corrosão com desplacamento na face inferior

Uma possível técnica de reparo é a remoção do material deteriorado e restauração da peça. De acordo com Helene [3], é necessário, primeiramente, retirar a área de concreto manchada devido ao processo de corrosão com o auxílio de um escarificador manual ou mecânico. Em seguida, retira-se os produtos de corrosão com lixa de ferro e reconstrói-se a peça com um material de consistência plástica, como por exemplo, concreto ou argamassa que permitam que a estrutura trabalhe de forma monolítica.

\subsection{Fissuras em linha na longarina e na transversina}

A ruptura decorrente de processos mecânicos ou físicos químicos é denominada fissura de acordo com Figueiredo [6]. Sendo que, a sua posição das fissuras, abertura e trajetória nas estruturas podem indicar suas possíveis causas.

Por meio da inspeção, foi constatado a presença de fissuras próximas da região dos apoios, próximas ao meio do vão da viga longitudinal, no meio do vão da transversina e ao longo da laje. Nesses casos, o reparo da manifestação pode não ser suficiente pois as estruturas apresentam indícios de estarem sob ação de esforços imprevistos, como por exemplo, esforços de flexão. As fissuras que caracterizam esforços de flexão na viga, segundo Dal Molin [7], ocorrem perpendicularmente às trajetórias das tensões principais de tração e apresentam-se com inclinação de $45^{\circ}$ na região dos apoios e aproximadamente vertical perto do meio do vão (Fig. 5). Na face interior da viga, as aberturas apresentam-se maiores e, próximo a linha neutra, menores, devido à localização das fibras mais tracionadas. Portanto, além do reparo da manifestação, pode-se fazer necessário realizar reforço da estrutura. 


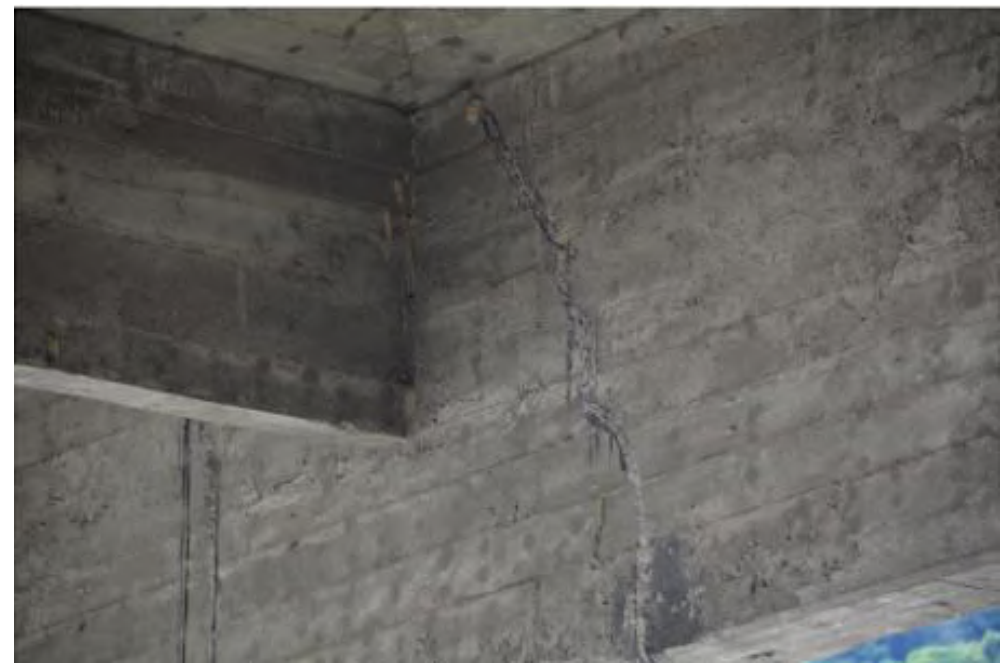

Figura 5: Fissura em $45^{\circ}$ na viga longitudinal

De acordo com Pimentel [8], uma possível solução de reparo de fissuras é a injeção de ligantes epoxídicos não plastificado ou polissulfetos que apresentam alongamento à ruptura superior à $100 \%$. O material deve ser relativamente flexível para acompanhar certa movimentação da fissura e apresentar resistência à tração maior que a do concreto utilizado no elemento. O autor descreve que, para realizar o reparo, é necessário instalar tubos de injeção por meio da perfuração do concreto, injetar a resina, e, após o término da injeção, deve-se cortar os tubos rentes ao elemento e preenchê-los com argamassa.

\subsection{Eflorescências}

Segundo Mehta e Monteiro [9], a manifestação eflorescência ocorre através do processo de carreamento do hidróxido de cálcio pela água que infiltra no interior do concreto, geralmente em caminhos preferenciais, como os proporcionados por fissuras. Os produtos carreados acumulam-se na superfície da estrutura, gerando manchas esbranquiçadas (Fig. 6). Como o $\mathrm{Ca}(\mathrm{OH}) 2$ é responsável pela elevada alcalinidade do concreto, esse processo pode diminuir $0 \mathrm{pH}$ da estrutura, proporcionando um meio propício para o surgimento da corrosão das armaduras.

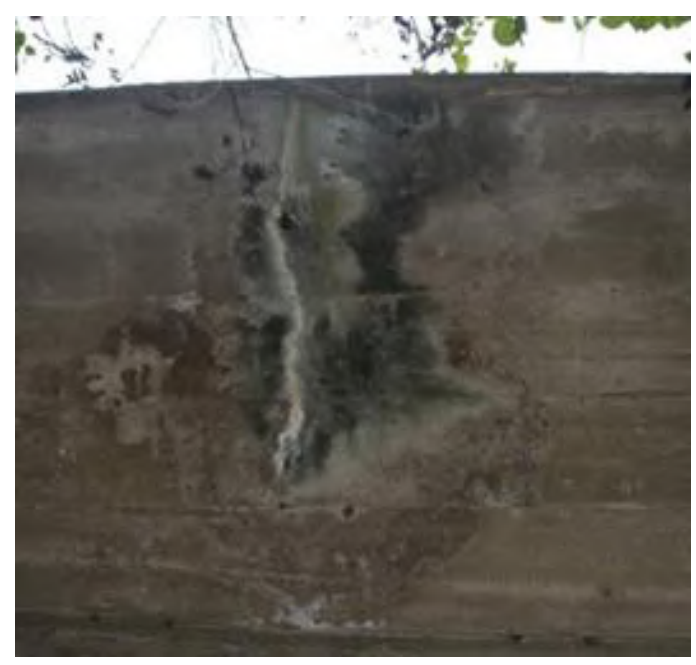

Figura 6: Fissura e eflorescência na laje 
Para realizar o reparo da estrutura, de acordo com Silva [10], precisa-se limpar a superfície através da técnica de escovação e lixamento manual ou mecânica, por meio de equipamentos como lixas manuais ou mecânicas, além de realizar a limpeza com jato simples de ar, pincel macio ou com jatos d'água aplicados com equipamento de alta pressão. Recomenda-se também, realizar o reparo da fissura que ocasionou o caminho preferencial da água, responsável pela lixiviação por meio da técnica citada no ítem 3.2.

\subsection{Manchas de umidade}

As manchas em uma Obra de Arte Especial, em geral, decorrem da falta de estanqueidade de elementos como juntas de dilatação ou de problemas no sistema de drenagem como falta de pingadeiras, drenos entupidos, buzinotes quebrados e etc. As consequências dessa manifestação variam desde alterações estéticas até comprometimento de elementos estruturais, como, por exemplo, favorecimento da corrosão da armadura.

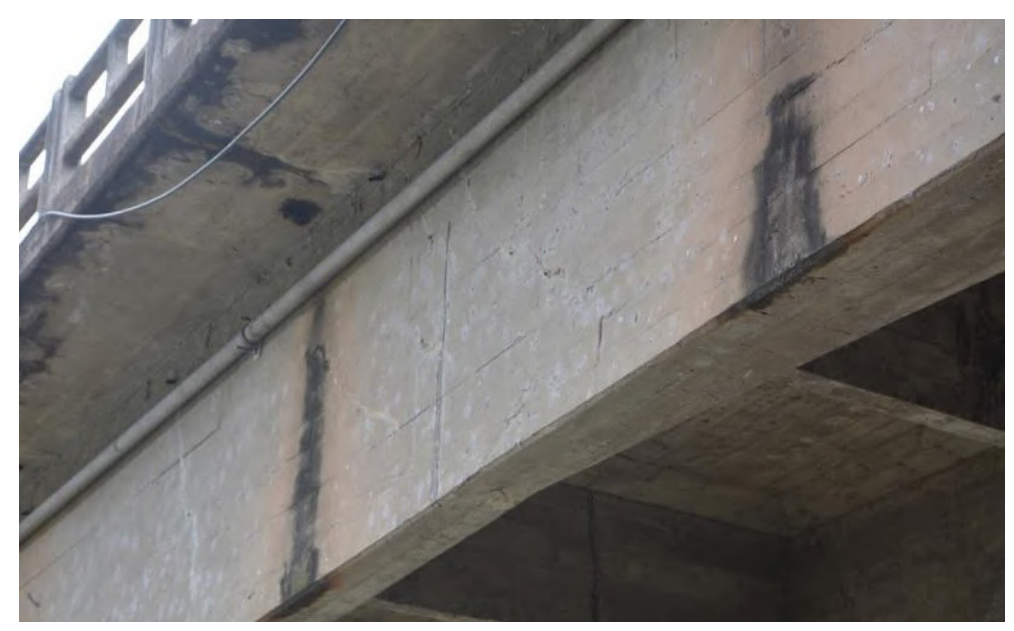

Figura 7: Manchas de umidade na laje e na viga principal

Neste caso (Fig. 7), sugere-se reparo da manifestação através da técnica de lixamento e lavagem já apresentada para a manifestação lixiviação. A fim de evitar recorrência, deve-se ser executado um sistema com drenos e buzinotes.

\subsection{Danos no aparelho de apoio}

Por meio da inspeção, constatou-se que os aparelhos de apoio se apresentava um relativo esmagamento e ressecamento (Fig. 8). Imprescindível realizar reparo do elemento, pois o seu mal funcionamento pode acarretar em problemas estruturais. Também deve ser realizada uma Inspeção Especializada, pois os danos no aparelho de apoio podem ter sido gerados por esforços excessivos na estrutura. 
SILVA, A. C. G.; CAMPOS, G. R.; SANTOS FILHO, M. L., ANÁLISE DE MANIFESTAÇÕES PATOLÓGICAS EM OBRAS DE ARTE ESPECIAIS - ESTUDO DE CASO E PROPOSTAS DE RECUPERAÇÃO. $2^{\circ}$ Simpósio Paranaense de Patologia das Construções (20 SPPC), artigo 2SPPC1014, pp. 159-170, 2017. DOI: 10.4322/2SPPC.2017.014

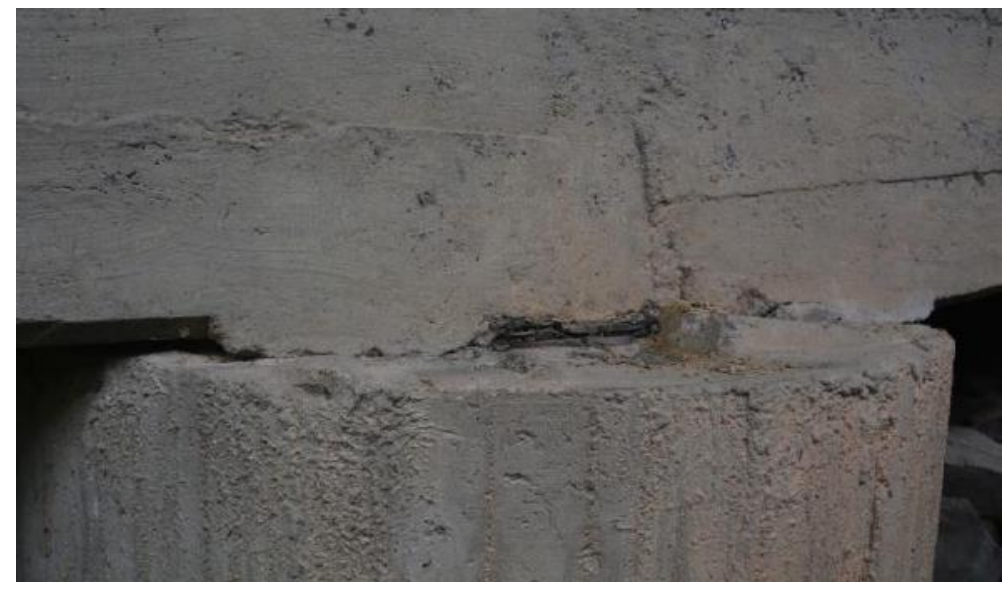

Figura 8: Aparelho de apoio

Deve ser realizado o macaqueamento da estrutura e a substituição do aparelho de apoio.

\subsection{Recalque do aterro de aproximação}

De acordo com Paiva [11], é comum aparecer um desnível próximo ao início da ponte devido a movimentação do aterro de acesso muitas vezes proporcionada pela sua má compactação, como evidenciado na Fig. 9. Tal situação é desvantajosa pois prejudica a segurança dos veículos devido ao efeito de solavanco.

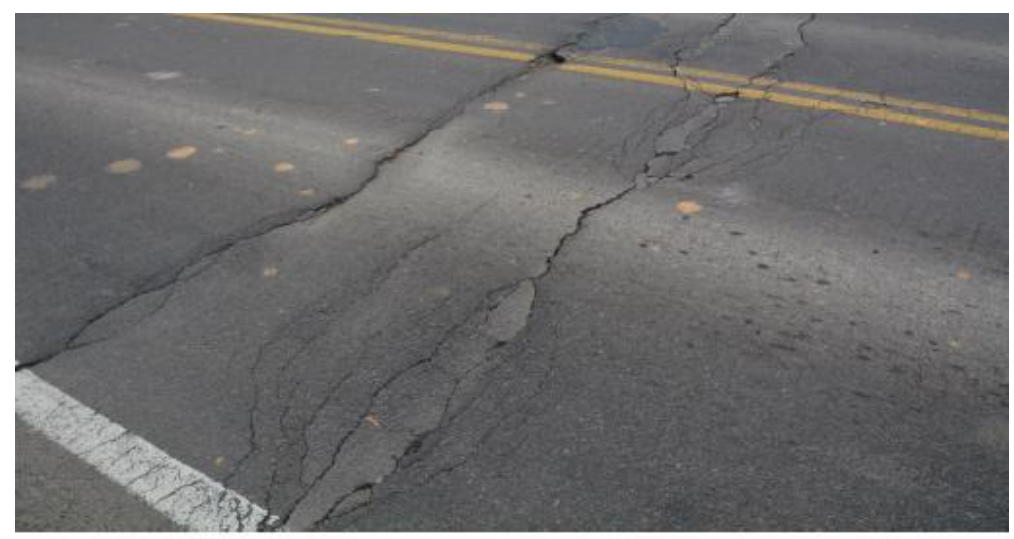

Figura 9: Deformações no pavimento devido ao recalque no aterro de aproximação

Segundo Paiva [11], para realizar o reparo da manifestação, é necessário interromper o tráfego e preencher o greide com material compactado, a fim de nivelá-lo. Feito isso, deve-se recapear o local.

\subsection{Desgaste e buracos no pavimento}

Segundo a norma DNIT 005/2003 [12] os defeitos nos pavimentos flexíveis podem ser identificados como fissuras, trincas superficiais, desgaste, escorregamento, buracos, entre outros. As fissuras são as primeiras manifestações patológicas que surgem no pavimento, caso não haja manutenção preventiva as fissuras podem se desenvolver com a infiltração da água e pela força do tráfego resultando em buracos 
SILVA, A. C. G.; CAMPOS, G. R.; SANTOS FILHO, M. L., ANÁLISE DE MANIFESTAÇÕES PATOLÓGICAS EM OBRAS DE ARTE ESPECIAIS - ESTUDO DE CASO E PROPOSTAS DE RECUPERAÇÃO. $2^{\circ}$ Simpósio Paranaense de Patologia das Construções (20 SPPC), artigo 2SPPC1014, pp. 159-170, 2017. DOI: 10.4322/2SPPC.2017.014

no pavimento, conhecidos também como "panelas". Foi observado em campo um remendo superficial, a presença de trincas desgaste do pavimento com início do desenvolvimento de buracos, como mostrado na Fig. 10.

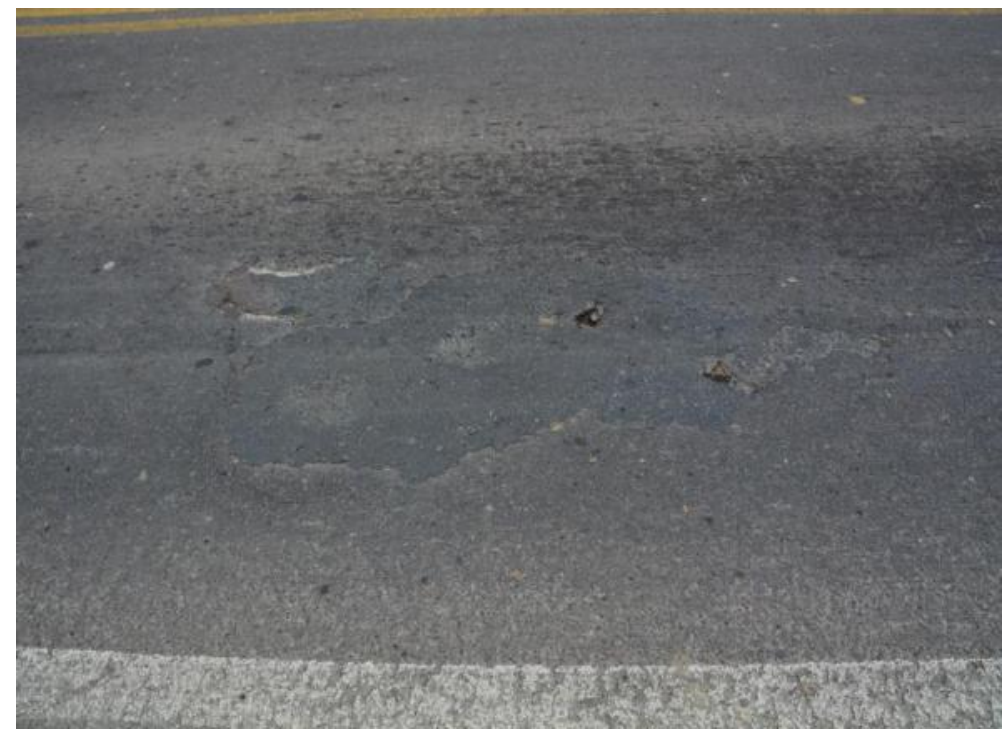

Figura 10: Remendo e buracos no pavimento.

Seguindo as recomendações da norma DNIT 321/2009 [13], deve-se remover todo material da área degradada e realizar um corte no pavimento para obter bordas verticais à uma distância de $30 \mathrm{~cm}$ da parte danificada. A região deve receber uma pintura de ligação e só então o preenchimento da cava com mistura betuminosa quente que deve ser compactada com rolo pneumático ou similar.

\subsection{Desgaste superficial do concreto}

Segundo Mehta e Monteiro [9] o desgaste superficial do concreto pode ocorrer de três formas distintas: pela erosão, abrasão e cavitação. No estudo de caso, os pilares localizados no leito do rio apresentam desgaste da superfície do concreto causada pela erosão, apresentando já agregados expostos. De acordo com Mehta e Monteiro [9] a erosão ocorre devido ao choque de partículas sólidas suspensas em um fluído líquido contra o concreto (Fig. 11).

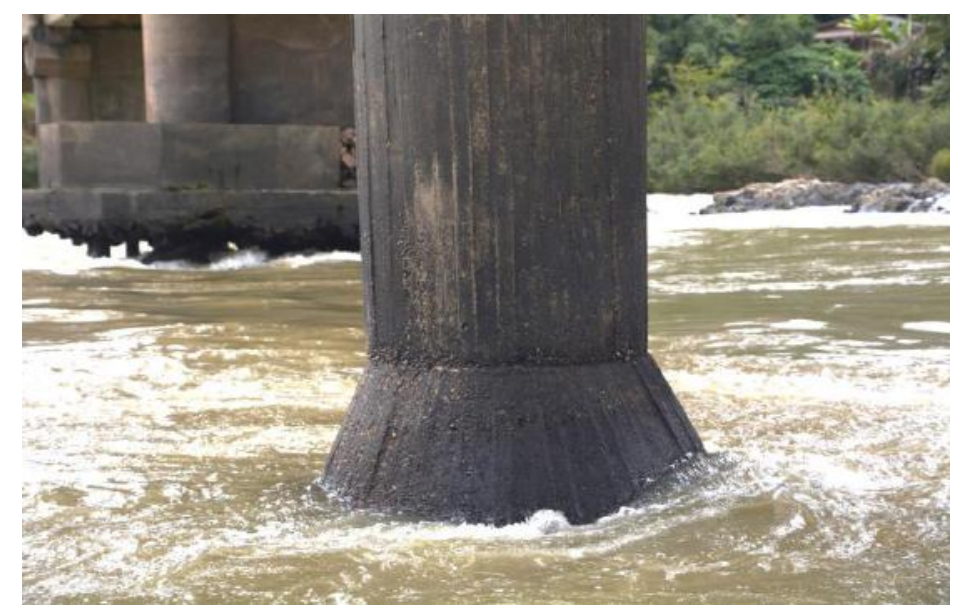

Figura 11: Desgaste superficial no concreto no pilar 
Para reparo da superfície é necessário isolar o elemento para averiguar se há danos também na parte submersa. Para tal, podem ser construídas ensecadeiras de diferentes modos, com sacos areia e material argiloso ou areia e cimento. Após determinação da área de reparo, deverá ser realizada a escarificação e limpeza da superfície escarificada. A reconstituição da superfície é feita com preenchimento da área com argamassa ou concreto, dependendo da dimensão do reparo.

\subsection{Nicho de concretagem}

De acordo com o DNIT [14], nichos ou ninhos são vazios nas peças de concreto causadas por erros na concretagem que impedem que a argamassa complete todos os locais dentro da forma, deixando espaços vazios entre os agregados. Os nichos de concretagem diminuir a seção transversal da peça, podem facilitar a entrada de agentes agressivos, e em alguns casos deixam a armadura exposta ao ambiente. Foi constatada essa manifestação patológica em um dos pilares da OAE, conforme Fig. 12.

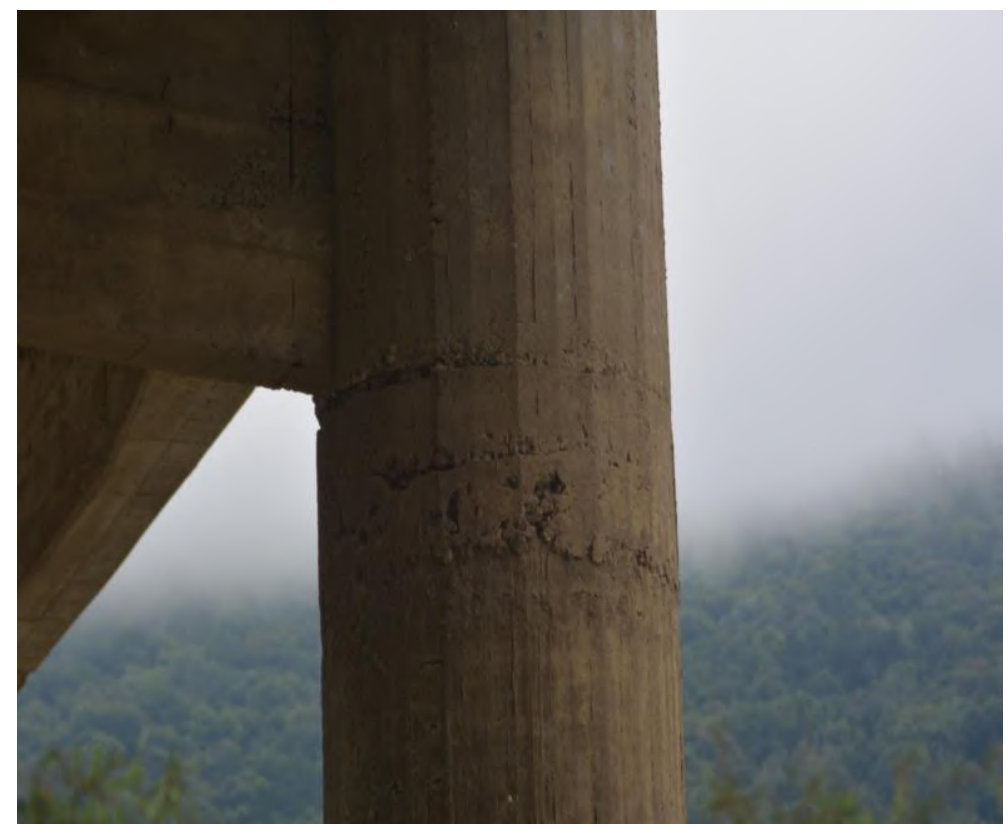

Figura 12: Nicho de concretagem no pilar

Deve-se verificar se a armadura foi ou não exposta devido aos vazios (Fig. 12), pois se foi exposta é necessário seguir os mesmos procedimentos de reparo para corrosão de armadura com desplacamento. Caso contrário, deve ser feita a escarificação da região, remover o material segregado ao redor do nicho. Em seguida faz-se a limpeza e preparação da superfície para receber a nova argamassa ou graute. Por fim, preenche-se a área com o material escolhido, realizando a cura adequada.

\section{Considerações Finais}

As técnicas de reparo propostas visam melhorar o desempenho da Obra de Arte Especial e por consequência aumentar sua vida útil. Dentre as manifestações citadas, é necessário separar as manifestações devido à vícios construtivos, falta de 
manutenção ou problemas estruturais. Os reparos propostos para os casos de manifestações consequentes de vícios construtivos, assim como as consequentes da falta de manutenção, promovem reabilitação efetiva da estrutura nestes quesitos. Porém, as manifestações devido à problemas estruturais, como por exemplo as fissuras na viga longitudinal e laje, necessitam ser estudadas através de uma Inspeção Especializada e, caso necessário, realizar reforço. No caso das fissuras, é imprescindível que, além do reforço, também seja executado o reparo, pois elas tornam-se caminhos preferenciais para percolação de fluídos pela estrutura, podendo desencadear outros problemas, como eflorescências, manchas de umidade e até processos corrosivos.

\section{Referências}

[1] Fonte, T.F. (2007). Pontes protendidas de madeira: Alternativa técnicoeconômica para vias rurais. Jaboticabal, v.27, n.2, p.552-559. Brasil.

[2] DNIT (2004). Manual de Inspeções de Pontes Rodoviárias. 2. Ed. Rio de Janeiro, Brasil.

[3] Helene, P. R.L. (1986). Corrosão em armaduras para concreto armado. Editora Pini - Instituto de pesquisas Tecnológicas IPT, 47p. São Paulo, Brasil.

[4] Santos, A V.B. (2015). Corrosão de armadura em estruturas de concreto devido à carbonatação. Revista Especialize On-line IPOG, ed no 10, Vol. 01/ 2015. dez. 2015. ISSN 2179-5568. Goiânia, Brasil.

[5] Polito, G. (2006). Corrosão em Estruturas de Concreto Armado: Causas, Mecanismos, Prevenção e Recuperação. Universidade Federal de Minas Gerais. Belo Horizonte, Brasil. Disponível em: http://www.cecc.eng.ufmg.br/trabalhos/pg1/Monografia\%20Giulliano\%20Polito.p df. Acesso em: 15 mar. 2017.

[7] Dal Molin, D.C.C. (1998) Fissuras em Estruturas de Concreto Armado: Análise das Manifestações Típicas e Levantamento de Casos Ocorridos no Estado do Rio Grande do Sul. Universidade Federal do Rio Grande do Sul. Porto Alegre, Brasil.

[6] Figueiredo, E.J.P. (1989). Terapia das construções de concreto: metodologia de avaliação de sistemas epóxi destinadas a injeção de fissuras passivas das estruturas de concreto. Porto Alegre, Brasil.

[8] Pimentel, C.C.D. Patologia de Concreto e Recuperação de Estruturas: Injeções de resina em estruturas de concreto. IBRACON - Instituto Brasileiro de Concreto. São Paulo, Brasil.

[9] Mehta, P. Kumar; Monteiro, P. J.M. (1994). Concreto: Estrutura, Propriedades e Materiais. Tradução de Paulo Helene et al. 1. ed. São. PINI, 580p. ISBN 857266- 040- 2. São Paulo, Brasil.

[10] Silva, E. A. (2006). Técnicas de recuperação e reforço. TCC (Graduação) Curso de Engenharia Civil, Universidade Anhembi Morumbi, São Paulo, Brasil

[11] Paiva, C.E.L. (2011). Considerações na execução de aproximações de Obra de Arte Especial. CONINFRA 2011 - 50 Congresso de Infraestruturas de Transportes. São Paulo, Brasil. 
SILVA, A. C. G.; CAMPOS, G. R.; SANTOS FILHO, M. L., ANÁLISE DE MANIFESTAÇÕES PATOLÓGICAS EM OBRAS DE ARTE ESPECIAIS - ESTUDO DE CASO E PROPOSTAS DE RECUPERAÇÃO. $2^{\circ}$ Simpósio Paranaense de Patologia das Construções (20 SPPC), artigo 2SPPC1014, pp. 159-170, 2017. DOI: 10.4322/2SPPC.2017.014

[12] DNIT 005/2003 (2003). Defeitos nos pavimentos flexíveis e semi-rígidos Terminologia. Diretoria de Planejamento e Pesquisa / IPR. Rio de Janeiro, Brasil. Disponível em: http://ipr.dnit.gov.br/normas-emanuais/normas/terminologia-ter/dnit005_2003_ter.pdf. Acesso em: 19 mar. 2017.

[13] DNER - ES 321/97 (Revisada em 2009). Pavimentos flexíveis - Recuperação de defeitos em pavimentos - Especificação de serviço. Instituto de Pesquisas Rodoviárias. Rio de Janeiro, Brasil. Disponível em: http://www1.dnit.gov.br/normas/PAV\%20Flexiveis\%20-

\%20Recup\%20de\%20Defeitos\%20em\%20Pav\%20Flexiv.pdf. Acesso em: 19 mar. 2017.

[14] DNIT (2010). Manual de recuperação de pontes e viadutos rodoviários. Rio de Janeiro, Brasil. Disponível em: http://ipr.dnit.gov.br/normas-emanuais/manuais/documentos/744_manual_recuperacao_pontes_viadutos.pdf. Acesso em: 15 mar. 2017. 